\title{
HUBUNGAN WORK LIFE BALANCE DENGAN KEPUASAN KERJA PADA GURU DI SMK KABUPATEN PATI
}

\author{
Ellyda Yohan Pranindhita', Doddy Hendro Wibowo ${ }^{2}$ \\ Email: ellydayohanpranindhita07@gmail.com ${ }^{1}$,doddy.wibowo@uksw.edu \\ Fakultas Psikologi, Universitas Kristen Satya Wacana Salatiga ${ }^{1,2}$
}

\begin{abstract}
This study aims to determine the relationship between work life balance and job satisfaction. This study uses a correlational quantitative method. The number of participants in this study were 36 female teachers who were married. The technique used was the saturated technique all members of the population were used as samples. The research data was taken from SMK in Pati Regency. Data used for the work life balance scale from Fisher, Bulger and Smith (2009) and the Job Satisfaction Scale use the Job Satisfaction Survey Scale from Spector (1997). Data analysis using Pearson Product Moment correlation using SPSS for windows version 16.0. The results of this study there is no relationship between work life balance and job satisfaction $(r=-0.035)$. This shows that job satisfaction of married female teachers is not affected by work life balance. Keywords : Work Life Balance, Job Satisfaction.
\end{abstract}

\begin{abstract}
Abstrak
Penelitian ini bertujuan untuk mengetahui hubungan work life balance dengan kepuasan kerja. Penelitian ini menggunakan metode kuantitatif korelasional. Jumlah pertisipan dalam penelitian ini sebanyak 36 guru wanita yang telah menikah. Teknik yang digunakan adalah teknik jenuh yaitu semua angota populasi digunakan sebagai sample. Data penelitian ini diambil dari SMK di Kabupaten Pati. Data yang digunakan untuk Skala work life balance dari Fisher, Bulger dan Smith (2009) dan Skala Kepuasan Kerja menggunakan skala Job Satisfaction Survey dari Spector (1997). Analisis data menggunakan kolerasi Product Moment Pearson menggunakan bantuan program SPSS for windows versi 16.0. Hasil dari penelitian ini tidak adanya hubungan antara work life balance dan kepuasan kerja $(\mathrm{r}=-0,035)$. Hal ini menunjukan kepuasan kerja pada guru wanita yang telah menikah tidak di pengaruhi oleh work life balance.
\end{abstract}

Kata kunci : Work Life Balance, Kepuasan Kerja.

\section{PENDAHULUAN}

Perempuan di era modern ini mampu bekerja baik dalam bidang pemerintahan, bidang industri hingga bidang pendidikan. Hal yang mendorong perempuan bekerja adalah untuk memenuhi kebutuhan keluarga di era pertumbuhan ekonomi yang pesat ini. Pada saat ini, perempuan dapat melakukan pekerjaan yang dilakukan oleh laki-laki, salah satunya di bidang pendidikan. Dalam bidang pendidikan ini memegang peranan penting dalam perkembangan individu dalam mempersiapkan tujuan masa depan. Tentunya dalam bidang pendidikan juga diperlukan adanya tenaga pendidik yaitu guru. Guru merupakan tenaga pendidik yang memiliki tugas utama mengajar, mendidik, membimbing, melatih dan menilai peserta didik. Guru memiliki pengaruh yang besar dalam proses pembelajaran salah satunya adalah keberhasilan belajar siswa. Esi, Purwaningsih dan Okianna (2016), bukan hanya melalui tugas utama yang diperlukan seorang guru agar siswanya mampu mencapai keberhasilnya belajar

Adapun tuntutan sebagai guru yang perlu dimiliki yaitu sebagai fasilitator dan motivator bagi peserta didik. Peran 
sebagai fasilitator ini diharapkan mampu memudahkan peserta didik untuk belajar dalam suasana yang menyenangkan dan berani mengungkapkan pendapat secara terbuka. Kemudian peran sebagai motivator yaitu memberi semangat dan mendorong siswa agar termotivasi dalam kegiatan belajar mengajar selain itu peran motivator juga dapat memberikan penghargaan terhadap hasil kerja peserta didik.

Selain memiliki tututan peran bagi peserta didik, guru juga memiliki tuntutan kompetensi yang harus dimiliki oleh guru itu sendiri. Yaitu pedagodik (strategi pembelajaran), menguasai karakteristik peserta didik dan teori belajar dengan prinsip pembelajaran yang mendidik, pengembangan kurikulum, komukasi, penilaian dan evaluasi peserta didik. Kepribadian yaitu, bertindak sesuai dengan norma agama, sosial, hukum, dan kebudayaan, menunjukan kepribadian yang teladan dan memiliki rasa tanggung jawab yang tinggi. Sosial yaitu, dengan menjalin komunikasi yang baik pada orang tua siswa, sesame guru, peserta didik dan masyarakat bertindak obyektif dan tidak diskriminatif. Kemudian profesional yaitu penguasaan materi, struktur, konsep dan pola pikir keilmuan yang mendukung mata pelajaran yang diampu dan mengembangkan keprofesionalan melalui tindakan yang reflektif. Dalam Wati, Suparno, dan Yunita (2011), pendidikan seorang guru sebagai pengajar yang menjadi faktor penentu keberhasilan siswa dalam dunia pendidikan. Menurut Martoyo (2000), kepuasan kerja dapat memunculkan suatu perasaan dengan adanya pekerjaan yang sesuai antara kemampuan, ketrampilan dan harapan yang memunculkan rasa puas pada pekerjaannya.

Kepuasan kerja adalah sesuatu yang seseorang dapat rasakan tentang pekerjaannya dan aspek diluar pekerjaannya yang dianggap memuaskan (Spector, dalam Wenno, M. W., 2018). Kepuasan kerja memunculkan perasaan seseorang terhadap pekerjaannya. Hal ini akan tampak pada sikap positif individu terhadap pekerjaan dan segala sesuatu yang dihadapi di lingkungan kerjanya. Aspek - aspek kepuasan kerja menurut Spector (1997): a) Gaji/ upah yaitu, kepuasan dan rasa adil dari segi jumlah gaji yang sesuai dengan pekerjaan; b) Promosi yaitu, kepuasan atas peluang promosi yang didaptkan; c) Supervisi yaitu, kepuasan pada atasan dalam memberikan tugas managerial; d) Tunjangan yaitu, kepuasan yang didapat melalui tunjangan berupa fasilitas, liburan dan yang lain; e) Penghargaan yaitu, kepuasan didapat dari penghargaan atas 
kinerja yang baik; f) Peraturan/ prosedur kerja yaitu, kepuasan pada prosedur kerja yang ada; g) Rekan Kerja yaitu, kepuasan pada hubungan antar rekan kerja; h) Pekerjaan yaitu, kepuasan pada pekerjaan yang dilakukan; i) Komunikasi yaitu, adanya komunikasi yang baik dalam organisasi.

Kepuasan kerja adalah sikap yang ditujukan seorang individu terhadap pekerjaanya (Robbins dan Judge, 2015). Kepuasan kerja merupakan persepsi individu tentang seberapa baik pekerjaannya yang dinilai penting (Tarigan dan Ratnaningsih, 2018). Kepuasan kerja adalah suatu persepsi individu dalam mencapai kepuasan dalam pekerjaannya dan diluar pekerjaannya. Selain itu kepuasan kerja merupakan sejauh mana ia mampu menerima nilai nilai aspek dalam pekerjaan. Faktor-faktor yang mampu mempengaruhi kepuasan kerja yaitu pemenuhan kebutuhan adanya kesempatan kerja untuk memenuhi kebutuhan sehari hari jika kebutuhan sehari- hari dan memenuhi harapan tercapainya hasil atau harapan dalam melakukan pekerjaannya.

Menurut Handayani (2013), dalam dunia kerja perempuan yang bekerja memiliki nilai positif maupun negatif. Nilai positif yang dapat diambil perempuan dapat ikut membantu perekonomian keluarga dan memiliki hubungan yang setara dengan suami, sedangkan nilai negatifnya kesulitan untuk membagi waktu dengan keluarga terlebih dengan anak, muncul persoalan dalam keluarga dan pekerjaan. Menurut Kinnunen dan Mauno (dalam Handayani, 2013) sehubungan dengan konflik yang dihadapi akan berdampak pada kepuasan sebagai seorang individu, kepuasan dalam perkawinan, kepuasan terhadap pekerjaan yang rendah.

Untuk membagi keseimbagan waktu antara pekerjaan dan keluarga dalam istilah psikologi disebut dengan Work Life Balance. Work Life Balance yaitu suatu individu dapat seimbang dalam menjalankan perannya baik dalam pekerjaan maupun kehidupan diluar pekerjaan (McDonald, Brown\& Bradley, 2005). Dalam menjalankan perannya dalam dunia kerja guru wanita juga memilki peran penting dalam keluarga. Menurut Handayani (2013), ketika seseorang mampu berbagi peran dengan baik individu akan merasakan adanya kepuasan dalam menjalankan kedua perannya walaupun tetap ada konflik dalam keseimbangan kerja keluarga. Seorang individu yang mampu bertahan dalam menjalankan dua peran secara seimbang akan mendapatkan kepuasan dalam menjalani kedua perannya. 
Schermerhorn (dalam Ganapathi 2016) mengungkapkan bahwa work life balance adalah kemampuan menyeimbangkan tutntutan pekerjaan dan kebutuhan pribadi keluarga seseorang individu. Work life balance kondisi dimana seseorang membutuhkan keseimbangan tuntutan peran dalam keluarga dan pekerjaannya supaya dapat meminimalkan konflik yang kemudian individu tersebut dapat meningkatkan perasaan puas dalam bekerja (Paramita, 2006). Definisi menurut Fisher, Bulger dan Smith (2009) work life balance usaha yang dilakukan oleh seorang individu untuk menyeimbangkan dua peran yang sedang dijalankan. Work life balance memiliki 4 dimensi, yaitu : a) Work Interference with Personal Life (WIPL) dilihat dari sejauh mana pekerjaan seorang individu dapat mengganggu kehidupan pribadi individu tersebut; b) Personal Life Interference with Work (PLIW) dilihat sejauh mana kehidupan pribadi seorang individu dapat menggangu pekerjaannya; c) Personal Life Enchancement of Work (PLEW) dilihat dari sejauh mana kehidupan pribadi seorang individu dapat meningkatkan performa individu dalam pekerjaannya; d) Work Enhancement of Personal Life (WEPL) dilihat dari sejauh mana pekerjaan dapat meningkatkan kualitas kehidupan pribadi individu. Work life balance mempengaruhi kepuasan kerja individu yang telah menikah karena individu yang telah menikah membutuhkan keseimbangan baik pada pekerjaannya maupun kehidupan pribadinya (Nurendra dan Saraswati, 2017).

Berdasarkan wawancara dengan beberapa narasumber SMK di Kabupaten Pati pada bulan Februari 2018. Kepuasan kerja diperoleh dari penghargaan atau apresiasi yang di berikan atasan ataupun rekan kerja kepada guru yang memberikan performa yang baik, namun sebagian merasakan ketidakpuasan kerja didapat melalui gaji yang didapatkan. Terlebih pada guru yang telah berkeluarga merasa kurang puas dengan gaji yang didapatkan. Gaji yang didapat bukan hanya untuk kebutuhan pribadi namun juga kebutuhan keluarga yang lainnya. Selain itu kurangnya komunikasi antar karyawan yang menimbulkan kesalahpahaman persepsi yang menimbulkan ketidakpuasan dalam bekerja.

Berdasarkan beberapa penelitian sebelumnya yang dilakukan oleh Wenno (2018), mengenai hubungan antara work life balance dan kepuasan kerja menunjukan adanya hubungan yang positif dan signifikan antara work life balance dan kepuasan kerja. Lalu pada penelitian Tarigan dan Ratnaningsih 
(2018), menunjukan adanya hubungan yang signifikan antara work life balance dan kepuasan kerja. Pada kedua peneilitian diatas menunjukan bahwa semakin tinggi work family balance maka kepuasan kerja juga tinggi dan sebailknya jika work life balance rendah maka kepuasan kerja juga rendah. Sedangkan dalam penelitian Maeran, Pitarelli \& Cangiano (2013), menunjukan bahwa work life balance memiliki kolerasi yang negatif terhadap kepuasan kerja pada 286 guru di Provinsi Vicenza, Italia. Dalam penelitian ini work life balance meliliki hubungan negatif dengan faktor-faktor yang terkait dengan kepuasan kerja.

\section{METODE PENELITIAN}

Penelitian ini adalah jenis penilitian kuantitatif dengan metode penelitian korelasional. Dalam proses pengambilan data ini dilakuan pada bulan April 2019. Peneliti menggunakan skala kuesioner dalam pengambilan data dalam penelitian ini. Skala kuesioner ini disebarkan oleh peneliti di SMK Kabupaten Pati. Subjek yang diambil oleh peniliti ini adalah guru wanita yang telah menikah dengan rentang lama mengajar selama 6-35 tahun dan memiliki latar belakang pendidikan S1 dan S2. Peneliti membatasi pengambilan subjek yaitu pada guru SMK di Kabupaten Pati yang telah menikah. Total subjek yang peneliti dapatkan adalah 36 subjek sesuai dengan sampel yang peniliti tetapkan.

Alat ukur yang digunakan dalam work life balance pada penelitian ini adalah skala yang disusun berdasarkan dimensi-dimensi dari Fisher, Bulger, dan Smith (2009). Dalam skala tersebut memiliki 24 aitem setelah di diskriminasi menjadi 15 aitem dengan koefisien reliabilitas 0,823 . Ini menunjukan bahwa skala work life balance memiliki reliabilitas yang cukup baik. Alat ukur yang digunakan untuk mengukur Kepuasan Kerja adalah skala Job Satisfaction Survey yang dibuat oleh Spector (1997). Dalam skala tersebut memiliki 36 aitem setelah di diskriminasi menjadi 28 aitem dengan koefisien reliabilitas 0,866 . Ini menunjukan bahwa skala kepuasan kerja memiliki reliabilitas yang cukup baik.

Untuk mengetahui hubungan work life balance dan kepuasan kerja pada guru SMK di Kabupaten Pati dilakukan dengan uji korelasi Product Moment Pearson dengan bantuan program SPSS.

\section{HASIL DAN PEMBAHASAN.}

Dari hasil penelitian data deskriptif diketahui work life balance memiliki skor minimum 28 dan maksimum 56 $(\mathrm{M}=44,19, \quad \mathrm{SD}=6,903) . \quad$ Sedangkan kepuasan kerja memiliki skor minimum 82 dan maksimum $120(\mathrm{M}=100,50, \mathrm{SD}=$ 
11.254). Uji Normalitas yang diperoleh dari penilitan ini dapat ketahui bahwa variable work life balance memiliki nilai sebesar $(0,668>0,05)$. Kemudian pada variable kepuasan kerja memiliki nilai sebesar $(0,643>0,05)$. Maka dapat dilihat kedua variable tersebut berdistribusi secara normal. Uji Linearitas dilakukan dengan test linearity dari kedua variable tersebut dapat dikatakan memiliki nilai $(0,463>0,05)$ maka kedua variable tersebut dikatakan linear. Uji Hipotesis penelitian menggunakan teknik Pearson Correlation. Uji korelasi ini menggunakan One -tailed. Hasil analisis kolerasi menjukan nilai $r=-0,035$ yang berarti kedua variable tersebut tidak memiliki hubungan antara work life balance dan kepuasan kerja atau secara khusus dapat dikatakan bahwa tidak ada hubungan anatara kedua variable work life balance dengan kepuasan kerja.

Pada hasil dari pengujian data ditemukan bahwa hasil pengujian data tidak mendukung hipotesis, yaitu adanya tidak adanya hubungan antara work life balance dengan kepuasan kerja pada guru wanita yang telah menikah. Maka dikatakan bahwa kepuasan kerja tidak dipengaruhi oleh work life balance. Dimensi - dimensi Fisher, Smith dan Burger (2009), yaitu work life balance yaitu, Work Interference with Personal
Life (WIPL), Work Enhancement of Personal Life (WEPL), Personal Life Enchancement of Work (PLEW) dan Personal Life Interference with Work (PLIW) tidak memengaruhi kepuasan kerja pada guru wanita. Individu melihat sejauh mana pekerjaan dapat mengganggu kehidupan pribadi individu. Adanya beban pekerjaan yang harus dilakukan sebagai tanggung jawab pekerjaan dan lebih banyak menghabiskan waktu untuk bekerja yang menyita waktu untuk kehidupan pribadinya. Namun dalam penelitian ini menunjukan bahwa individu tidak merasa terganggu dalam menjalankan kehidupan pribadinya dan tidak terpengaruhi oleh pekerjaan yang harus dijalankan Work Interference with Personal Life (WIPL). Adanya pelatihan yang diberikan oleh instansi tidak mempu untuk meningkatkan kualitas kehidupan pribadi individu karena pelatihan yang diberikan hanya dapat digunakan saat individu bekerja bukan dalam kehidupan pribadinya. Individu merasa pekerjaan tidak dapat meningkatkan kualitas kehidupan individu Work Enhancement of Personal Life (WEPL). Adanya perasaan senang yang dirasakan individu dalam kehidupan pribadinya belum tentu dapat membuat suasana hati menyenangkan saat bekerja hal ini dipengaruhi oleh suasana lingkungan sekitar, hal ini menunjukan 
bahwa kehidupan pribadi seorang individu dapat meningkatkan performa individu dalam bekerja Personal Life Enchancement of Work (PLEW). Kemudian muncul adanya masalah dalam kehidupan pribadi individu tidak dapat mengganggu kinerja individu dalam bekerja. Individu dapat fokus dalam pekerjaan yang sedang dijalankan tanpa terganggu dengan masalah yang terjadi dalam kehidupan pribadi individu Personal Life Interference with Work (PLIW).

Kepuasan kerja Kinicki dan Fugate (2016, dalam Tarigan dan Ratnaningsih, 2018) menyatakan adanya faktor yang memengaruhi kepuasan kerja yaitu, pemenuhan kebutuhan (need fulfillment) merupakan pemenuhan kebutuhan seorang individu dengan bekerja sesuai dengan tingkatan karakteristik. Instansi perlu menyesuaikan gaji yang diterima dengan level jabatan yang dimiliki oleh individu tersebut kerena dengan tingginya jabatan yang dimiliki maka tinggi pula tanggung jawab yang dimiliki dalam pekerjaannya. Selain itu adanya faktor ketepatan dalam waktu pembayaran gaji juga sebagai penentu meningkatnya dorongan dalam diri individu untuk bekerja lebih baik lagi dalam pekerjan yang diberikan oleh atasan.
Memenuhi harapan (met expectations) merupakan pemenuhan harapan seseorang tentang perbedaan yang diperoleh dari pekerjaan dan yang diharapkan dari pekerjaan. Ketidakpuasan individu karena kurangnya kesempatan promosi yang diberikan bukan hanya mempertimbangkan pengalaman kerja yang dimiliki individu tapi juga perlu diperhatikan adalah keterampilan yang diperlukan oleh seorang individu agar dapat menjalankan dengan baik tanggung jawab pekerjannya yang akan dilakukannya.

Memberikan kesempatan promosi kepada individu yang berprestasi untuk membentuk pribadi individu yang lebih bertanggung jawab agar individu tersebut dapat meningkatkan kehidupannya.

Keadilan (equity) merupakan kepuasan didapatkan oleh seorang individu diperlakukan di tempat kerja. Adanya keadilan dalam pembagian struktur organisasi bukan hanya individu yang telah lama bekerja di dalam instansi tapi juga dapat melibatkan beberapa individu yang tergolong baru untuk masuk dalam struktur organisasi agar terjalin komunikasi dan kerjasama agar tidak ada rasa tidak nyaman antar individu. Adanya keterbukaan untuk berpendapat antara atasan dan bawahan agar tiap individu dapat mengungkapkan ide atau gagasan - 
gagasan yang dimiliki untuk kemajuan instansi.

Hasil uji hipotesis dalam penelitian ini didukung dengan penelitian sebelumnya. Hal ini di dukung dengan penilitian dari Alianto (2008) yaitu kepuasan kerja tidak dipengaruhi oleh work life balance. Dalam penelitian sebelumnya menunjukan bahwa kepuasan kerja tidak di pengaruhi oleh work life balance. Tingkat work life balance yang tinggi tidak dapat meningkatkan kepuasan kerja, begitupun juga sebaliknya tingkat work life balance yang rendah tidak dapat menurunkan kepuasan kerja seorang individu. Kemudian dalam penilitian dari Maeran, Pitarelli dan Cangiano (2013) menujukan work life balance dengan kepuasan kerja memiliki korelasi negatif terhadap 286 guru di Italia. Adanya faktor faktor yang memiliki hubungan yang lemah terhadap kepuasan kerja.

Dalam penelitian tersebut menyebutkan bahwa kepuasan kerja hanya di peroleh guru yang berstatus belum berkeluarga. Dalam penelitian Shujat, Cheema dan Bhutto (2011) work life balance yang tinggi tidak dapat meningkatkan kepuasan kerja, begitu juga dengan work life balance yang rendah tidak dapat menurunkan kepuasan kerja. Penelitian tersebut menunjukan bahwa work life balance hanya memiliki sedikit pengaruh terhadap kepuasan kerja. Adapun faktor work life balnce yang seperti : tekanan pekerjaan, turn over pegawai, lamanya jam kerja memiliki korelasi lemah dan negatif serta tidak signifikan dengan kepuasan kerja.

\section{PENUTUP}

\section{Simpulan}

Hasil dari penelitian ini menunjukan bahwa tidak ada hubungan antara work life balance dan kepuasan kerja. Kepuasan kerja pada guru wanita yang telah menikah tidak di pengaruhi oleh work life balance.

\section{Saran}

Bagi peneliti selanjutnya yang ingin meneliti work life balance dan kepuasan kerja diharapkan dapat menambah sample responden agar lebih representatif sehingga penelitian dapat sesuai dengan yang diharapkan. Untuk peneliti selanjutnya agar dapat mengkaji kembali faktor- faktor yang akan digunakan dalam penelitian. Selanjutnya, diharapkan saat proses pengambilan data dapat di pantau langsung oleh peneliti.

Bagi instansi SMK di Kabupaten Pati diharapkan dapat meningkatkan kompensasi para guru berdasarkan kinerja dan prestasi yang telah di capai oleh para guru. Kebijaksanaan dalam pemberian kompensasi membuat karyawan merasa tercukupi secara keuangan untuk 
memenuhi kebutuhannya. Adanya motivasi dan dukungan dari atasan terhadap pekerjaan yang dilakukan oleh para guru. Hal tersebut dapat meningkatkan kepuasan kerja para guru dalam menjalankan pekerjaannya.

\section{DAFTAR PUSTAKA}

Arikunto, S. 1993. Prosedur Penelitian Suatu Pendekatan Praktik. Jakarta: Gramedia.

Arikunto, S. 2003. Prosedur Penelitian Suatu Pendekatan Praktik. Jakarta:Bina Aksara.

Arikunto, S. 2010. Prosedure Penelitian Suatu Pendekatan Praktik. Jakarta: Rineka Cipta.

As'ad, M. 2004. Psikologi Industri: Seri Ilmu Sumber Daya Manusia. Yogyakarta: Liberty.

Asepta, U. Y., \& Maruno, S. H. P. 2017. Analisis pengaruh work-life balance dan pengembangan karir terhadap kepuasan kerja karyawan PT. Telkomsel, TBK Branch Malang. Jurnal Ilmiah Bisnis dan Ekonomi Asia, 11(2), 77-85.

Alianto, A. 2008. Pengaruh Kompensasi dan Work life balance Terhadap Kepuasan Kerja Dimediasi Stres Kerja. Universitas Esa Unggul.

Azwar, S. 2008. Reliabilitas dan Validitas. Yogyakarta : Pustaka Pelajar.

Esi, Purwaningsih, E., \& Okianna. 2016. Peranan Guru Sebagai Fasilitator Dan Motivator Dalam Meningkatkan Hasil Belajar Di Kelas Xi SMK. Jurnal Pendidikan dan Pembelajaran, 5(10), 1-14.

Fisher, G. G., Bulger, C. A., \& Smith, C.
S. 2009. Beyond work and family:

A measure of work/nonwork interference and

enhancement. Journal of Occupational Health

Psychology, 14(4), 441.

Fisher-McAuley, G., Stanton, J., Jolton,J., \& Galvin, J. 2003. Modeling the relationship between work -life balance and organizational outcomes. Paper presented at the Annual Conference of the Society for Industrial-Organizational Psychology. 1-26.

Ganapathi, I. M. D.2016. Pengaruh worklife balance terhadap kepuasan kerja karyawan (studi pada PT. Bio Farma Persero). Jurnal Ecodemica: Jurnal Ekonomi, Manajemen, dan Bisnis, 4(1),125-135.

Greenhaus, J. H., Collins, K. M., \& Shaw, J. D. 2003. The relation between work-family balance and quality of life. Journal of Vocational Behavior, 63(3),510-531.

Handayani, A. 2013. Keseimbangan kerja keluarga pada perempuan bekerja: tinjauan teori border.Jurnal Psikologi, 21(2), 90-101.

James, A., \& Purba, S. D. 2017.Efek moderasi dukungan organisasi dan mediasi work-life balance pada pengaruh pengembangan karir terhadap kepuasan kerja (Studi kasus karyawan wanita di PT Bank Central Asia, Tbk.). Jurnal Manajemen, 14(1), 53-73.

Kinicki, A., \& Fugate, M. 2016. Organizational Behaviour: A practical, problem-solving approach ( $1^{\text {st }}$ ed.). New York: McGraw-Hill Education.

Maeran, R., Pitarelli, F., \& Cangiano, F. 2013. Work-life balance and job 
satisfaction among teachers. Interdisciplinary Journal of Family Studies, XVIII, 1,51-72.

Mariati. 2013. Pengaruh work-life balance dan burnout terhadap kepuasan kerja (pada perusahaan pengadaan alat kesehatan dan perlengkapan rumah sakit yang berlokasi di Jakarta Timur). Thesis. Universitas Atma Jaya Yogyakarta.

Martoyo Susilo, 2000. Manajemen Sumber Daya Manusia, Yogyakarta: BPFE

McDonald, P. K., Brown, K., \& Bradley, L. M. 2005. Explanations for the provision-utilisation Gap in WorkLife Policy., 20(1), 37-55.

Nurendra, A. M., \&Saraswati, M. P. 2017. Model peranan work life balance, stres kerja dan kepuasan kerja pada karyawan. Jurnal Psikologi Indonesia, 13(2),84-94.

Paramita, P. 2006. Analisis pengaruh work-family balance dan program family friendly terhadap kepuasan kerja(Studi kasus pada rumah sakit panti wilasa Citarum, Semarang). Jurnal Manajemen dan Bisnis, 10(1), 1-10.

Qodrizana, D. L \& Musadieq, M. A. 2018. Pengaruh work-life balance terhadap kepuasan kerja (Studi pada karyawan perempuan yayasan insan permata Tunggulwulung Kota Malang). Jurnal Administrasi Bisnis $(J A B) \mid$ Vol, 60(1),9-17.

PCplus Online. 2016. Mayoritas Karyawan Tidak Puas Terhadap Manajemen Perusahaan. Diunduh pada 05 Februari 2018 dari https://www.pcplus.co.id/2016/11/b aru-terbit/jobplanet-mayoritaskaryawan-tidak-puas-terhadapaspek-manajemen/
Rahmawati, A. 2016. Pengaruh keseimbangan kehidupan kerja (Work life balance) dan kepuasan kerja terhadap loyalitas guru SMK swasta di Kecamatan Cakung Jakarta Timur. Jurnal Manajemen Pendidikan, 7(1),15-24.

Rindyantika, A \& Safitri, N. 2014. Analisis kepuasan kerja karyawan berdasarkan job satisfation survey (Studi pada karyawan tetap kantor pusat pt. airindo sakti). Jurnal Ilmu Sosial dan Ilmu Politik. 7(1),23-29.

Robbins, S.P., \&Judge, T.A. 2015. Perilaku Organisasi. Edisi ke 16. Jakarta : Salemba Empat.

Sevilla, G Consuelo. 1993. Pengantar Metode Pennelitian. Jakarta: UIPRESS.

Shujat, S., Cheema, F., \& Bhutto, F, 2011. Impact of Work Life Balance on Employee Job Satisfaction in Private Banking Sector of Karachi. Journal of Managementand Social Sciences, 7(2), 8-15.

Spector, P.E. 1997. Job Satisfaction Application, Assesment, Causes, and Consuquences. Thousand Oaks, California: Sage Publications.

Sugiyono, M. 2011. Metode Penelitian Kuantitatif, Kualitatif dan $R \& D$. Bandung: Alfabeta.

Sugiyono, M. 2015. Metode Penelitian Kuantitatif, Kualitatif dan $R \& D$. Bandung: Alfabeta.

Tarigan, C. F., \& Ratnaningsih, I. Z. 2018. Hubungan Antara Work-Family Balance Dengan Kepuasan Kerja Pada Tenaga Kependidikan Di Universitas X, Empati, 7(3),244251.

Wati, S. E. E., Suparno, S., \&Yunita, R. D. 2011. Kepuasan kerja pada guru 
ditinjau dari jenis kelamin kepala sekolah. Jurnal Ilmiah Psikologi, 1(2), 140-145.

Wenno, M. W. 2018. Hubungan Antara
Work Life Balance Dan Kepuasan Kerja Pada Karyawan Di PT PLN Persero Area Ambon. Jurnal Maneksi, 7(1),47-54 